\title{
Goa na diáspora e na literatura indiana em língua inglesa
}

\author{
Goa in diaspora and in Indian literature in English
}

\author{
JOANA PASSOS
}

Resumo: Este artigo apresenta um breve enquadramento histórico do aparecimento de literatura goesa em língua inglesa, apontando algumas das suas caraterísticas. Em segundo lugar, aborda-se a literatura goesa da diáspora, visto que a literatura goesa em inglês está intrinsecamente associada às rotas de emigração da comunidade goesa. Por outro lado, aborda-se um dos mais reconhecidos romances da literatura goesa em língua inglesa, sobre Goa na atualidade. Trata-se de Skin (2010) de Margaret Mascarenhas. Por fim, analisamos dois romances do autor indiano Amitav Ghosh, sobre as comunidades de marinheiros e migrantes do Oceano Índico, entre os quais se conta a comunidade goesa.

Palavras-chave: Literatura goesa, emigração, Margaret Mascarenhas, Amitav Gosh

\begin{abstract}
This paper presents a historical perspective to comprehend the advent of Goan literature in English, highlighting some of its characteristics. Secondly, the dynamics of Goan literature in English is discussed as a literature of diaspora since it is intrinsically connected to routes of emigration by the Goan community. Then, one of the most acknowledged novels in contemporary Goan literature in English, Skin (2010), by Margaret Mascrenhas, is analysed. Finally, this paper addresses two novels by the Indian writer Amitav Gosh, who writes about communities of migrants and seamen in the Indian Ocean, among which the Goan community is represented.
\end{abstract}

Keywords: Goan literature, emigration, Margaret Mascarenhas, Amitav Gosh

\footnotetext{
* Investigadora Auxiliar no CEHUM - Centro de Estudos Humanísticos da Universidade do Minho. Doutora pela Universidade de Utrecht, Holanda.
} 


\section{1. oa na diáspora}

Quando, há algum tempo atrás, estudei a literatura de Goa em língua portuguesa (PASSOS, 2012), sempre parti do princípio que estava a estudar uma parte de um todo, que tinha outras formas de expressão em outras línguas, como o marati, o concani e o inglês. Antes de investir na procura de traduções para chegar à herança literária de Goa nas línguas autóctones, como conheço a língua inglesa, optei pela exploração desse outro arquivo, a fim de poder estabelecer as relações e os diálogos possíveis entre estas duas dimensões da vida literária de Goa, em línguas diferentes e com uma história diferente. Se a língua portuguesa em Goa está marcada pela história colonial e pelas vivências que esse contexto político impôs aos goeses nesse pequeno (mas produtivo) estado, a literatura goesa em língua inglesa está marcada pelo contexto de emigração. Para os goeses, investir no estudo da língua inglesa era a porta de entrada para uma carreira na Índia Britânica, como funcionários públicos, se por acaso havia acesso a uma educação mais prolongada, ou então, como músicos, cozinheiros, amas ou trabalhadores que prestavam serviços variados num contexto urbano como Mumbai (no século XIX e XX, "Bombaim/Bombay"; o nome da cidade mudou para Mumbai em 1995). Por contraste, para os que ficavam em Goa, as alternativas para se organizar um projeto de vida cingiam-se ao meio rural ou à pesca, sendo a aldeia a principal comunidade de referência.

Estabelece-se então como ponto de partida neste estudo a relação entre o estudo da língua inglesa por parte de goeses e a paralela definição de um projeto de vida associado à emigração. Mas falta focar esta relação na dimensão específica da atividade do escritor. Evidentemente, as elites também estudavam inglês como parte da sua formação, e seriam as elites goesas que teriam a preparação formal para se aventurarem na escrita literária. Transpondo elementos adquiridos a partir da prévia investigação sobre literatura goesa em língua portuguesa, como primeiro passo no estudo sobre a literatura goesa em inglês procurei publicações periódicas, visto que já tinha verificado que o aparecimento de um sistema de publicações regular, laico e não administrativo, ainda que incipiente, tinha nascido com o advento da imprensa periódica no século XIX. Por conseguinte, o mais provável seria que um autor goês que escrevesse em língua inglesa tentasse publicar os seus textos na imprensa. A alternativa seria tentar publicar de uma forma independente uma antologia poética ou um romance, e 
esse projeto implicaria avultados recursos financeiros, para além dos problemas de distribuição (a primeira livraria goesa, a casa Luso-Francesa, abriu em 1889), que, à partida, estão resolvidos na imprensa periódica: o escritor apenas apanha "boleia" da distribuição que um dado jornal ou almanaque já tem. No caso da escrita em língua inglesa por autores goeses, a publicação sobre a qual me debrucei foi a Indo-Portuguese Review (Calcutá, 1919-1933, mas com distribuição por várias cidades da Costa Oriental de Àfrica, como Mombaça), por ser a única referência que encontrei a uma publicação periódica, de língua inglesa, impulsionada por emigrantes goeses na Índia, e cuja natureza estaria mais próxima do almanaque, ou do jornal literário. ${ }^{12}$ Mesmo assim, a investigação não se revelou muito frutífera, pois os artigos dessa revista eram de carácter prático (avisos, anúncios, notícias), a par de alguns textos sobre a religião cristã e seus valores. Apenas um poeta chamado Joseph Furtado (1872-1947) era colaborador regular da Indo-Portuguese Review. A sua poesia era agradável, e era muito semelhante em termos de padrões estéticos e temáticos à dos poetas que publicavam nos Almanaques ou jornais literários de Goa, em língua portuguesa. Por ser um caso isolado, numa publicação destinada a uma comunidade particular, não me pareceu pista de trabalho muito promissora, e nessa altura, abandonei o poeta Joseph Furtado que, apesar de tudo, me cativou pela escrita graciosa e pela vivacidade do seu espírito.

Eu deveria, pensei na altura, tentar perceber qual o processo que implantou a escrita em língua inglesa por parte de autores indianos no resto do subcontinente. Só depois deveria tentar perceber o que se passou com os goeses que resolveram escrever em inglês. Não era a Índia Britânica o macro-contexto em que estavam inseridos os autores goeses que escreviam em inglês? De facto não, não era (esse macro-contexto, como veremos, depende de fluxos migratórios mais amplos), e eu estava errada, mas este desvio no percurso da investigação foi produtivo e importante. Por isso, peço que me acompanhem por momentos no mesmo erro. E onde começa então a história da escrita por indianos em língua inglesa?

1 O meu objeto de estudo é literário, seja na forma de poesia, ficção narrativa ou até drama/ peças radiofónicas. Não abordarei aqui panfletos, imprensa comum ou escrita administrativa. No entanto, existe um interessante estudo de Rochelle Pinto sobre a publicação de panfletos políticos ou boletins informativos que circulavam entre comunidades de emigrantes goeses, quer em inglês, quer em concani. Ver Between empires, print and politics in Goa (PINTO, 2005). 
É lugubremente famosa a "Minute on indian education" do Barão Thomas Babington Macaulay, a qual passo a citar, para começar esta história pelo princípio:

[I would agree with] The Honourable apellation of a "learned native" to a native who was familar with the poetry of Milton, the metaphysics of Locke, and the physics of Milton. But to mean to designate by that name only such persons as might have studied in the sacred books of the Hindoos all the uses of cusa-grass, and the mysteries of absorption into the deity [...]

I am quite ready to take the oriental learning at the evaluation of the orientalists themselves. I have never found one among them who could deny that a single shelf of a good European library was worth the whole native literature of India and Arábia. (MACAULY, 1835)

[[Concordaria com] A honrosa denominação de "nativo culto" atribuída a um nativo conhecedor da poesia de Milton, a metafísica de Locke ou as leis da Física de Newton. Mas atribuí-la àquelas pessoas que apenas estudaram nos livros sagrados dos Hindus todos os usos possíveis das mezinhas caseiras e os mistérios da fusão com a divindade [...]

Estou pronto a avaliar o saber oriental tal como o avaliam os próprios orientalistas. Nunca encontrei um que pudesse negar que uma boa estante de literatura europeia vale por toda a literatura da Índia e da Arábia.] (Minha tradução)

Se este senhor fosse uma pessoa qualquer, este discurso não teria tido importância nenhuma e seria reduzido ao seu provincianismo preconceituoso. Mas este senhor era o conselheiro do Lord William Bentick, Governador Geral da Índia, e estas ideias foram apresentadas ao seu Concelho para se decidir como gastar o dinheiro reservado para a educação dos indianos. Ora, na altura, a escolha balançava entre financiar o estudo daquilo que Macaulay chama "Persian and Sanskrit", ou, pelo contrário, estabelecer o ensino da língua e literatura inglesas nos colégios e universidades indianas. $O$ governo inglês optou pela segunda hipótese, e assim, a partir da década de 1830, as elites indianas começaram a ser formadas em contato com a tradição literária inglesa.

A primeira fase na afirmação de uma qualquer literatura local em contexto colonial passa pela fase de imitação, como aconteceu com os românticos goeses que começaram a escrever em língua portuguesa. Os indianos que começaram a 
escrever em inglês não foram diferentes. A crítica indiana Meenakshi Mukherjee publica em 1971 o famoso estudo Twice born fiction, onde se argumenta que a apropriação do género romance, e a inclusão de temas da modernidade na escrita dos autores indianos, ficou a dever-se à repercussão dos estudos formais em língua inglesa na Índia. Ao chamar à ficção indiana em inglês "Twice born fiction", Mukherjee está a atribuir-lhe um elevado valor, pois os Brahmanes, a mais reverenciada casta, também renascem (isto é, "nascem duas vezes") quando passam por determinados rituais purificadores que lhes permitem serem plenamente admitidos como membros da sua casta. Se Mukherjee valoriza esta herança estética integrada na cultura indiana e moldada pela criatividade dos seus autores, já Gauri Vishwanathan, num artigo de 1995 intitulado "The beginings of english literary study in British India", denuncia o ensino da língua inglesa na Índia como uma forma de propaganda política que procurava cultivar entre as elites indianas o consentimento da situação colonial. Fomentar a admiração pela cultura inglesa seria portanto uma forma de gerar apatia em relação à situação política da Índia, afastando a possibilidade de espíritos dissidentes. A verdade é que, apesar desse objectivo perverso, a língua inglesa se "entranhou" na vida cultural indiana.

O primeiro romance escrito em inglês por um indiano parece ter sido Rajmohan's wife, publicado em 1864 por Bankim Chandra Chatterjee, e que apareceu como um folhetim no jornal Indian Field. Ora, é precisamente este mesmo ano, 1864, aquele em que se começa a publicar em Goa a Ilustração Goana. Notem a simultaneidade dos dois processos no desenvolvimento de literaturas locais nas línguas apropriadas do colonialismo na Índia: a língua portuguesa e a língua inglesa.

Estabelecido este paralelo faltava descobrir o primeiro poeta a publicar em inglês. Imaginem o meu espanto, quando descubro que o poeta que eu tinha abandonado, na revistinha que circulava entre os emigrantes goeses, o acima referido Joseph Furtado, não era nem mais nem menos do que o primeiro poeta "indiano" a publicar em língua inglesa. Assim é referido Joseph de Souza na antologia Marginalized: indian poetry in English (2014, p. 10) publicada por uma investigadora da Universidade de Allabad, Smita Agwarval, na qual a editora inclui entre os poetas indianos de língua inglesa mais dois poetas com ascendência goesa: Eunice de Souza e Dom Moraes. 
Se os poetas goeses que escrevem em inglês são integrados na literatura indiana como membros de pleno direito, então se fossem traduzidos e conhecidos, os autores goeses de língua portuguesa seriam igualmente considerados autores indianos, uma vez que Goa faz parte da Índia? Tenho uma resposta parcial a esta pergunta. Mas essa resposta passa por uma desterritorialização, ou seja, pelas rotas de emigração, como veremos.

Em 2010, surge uma interessante antologia de literatura goesa, com o título Modern Goan Literature (2010), editada por Peter Nazareth, a qual revela cruzamentos insuspeitos entre África e Goa, em função de determinados fluxos migratórios. Nessa antologia também aparece, em tradução para o inglês, um excerto de um livro de Orlando da Costa, concretamente, o capítulo seis de $O$ signo da ira (1961), o que revela que ao nível da recepção e circulação de textos literários não existe necessariamente uma divisão estanque entre as diversas literaturas goesas em línguas diferentes, pelo menos no caso das literaturas em português e inglês. Pelo contrário, onde existirem traduções, parece verificar-se uma fácil integração de todas as vozes.

No que diz respeito ao universo da literatura goesa representado na antologia Modern Goan Literature (2010) verifica-se que integra vários géneros literários, e tem o mérito de dar uma visão panorâmica de escrita considerada como goesa, embora esta esteja frequentemente deslocalizada em relação a Goa ou ao subcontinente indiano. Peter Nazareth não faz uma distinção, nem uma reflexão teórica sobre os pressupostos que o levam a considerar que, por exemplo, uma narrativa sobre um maravilhoso jardineiro/filósofo de uma escola em Nairobi, intitulada Roses with the Grass, de Violet Dias Lannoy (NAZARETH, 2010, p. 144168), pode ou deve ser necessariamente considerada literatura goesa em língua inglesa. É por causa do passaporte do escritor? Em nossa opinião, os temas e o universo representado no texto deveriam definir o sistema literário a que pertence um texto, mas essa definição é útil quando se consideram literaturas nacionais, perfeitamente circunscritas, mesmo se em várias línguas e representando várias comunidades. A questão da migração, ou daquilo que em inglês já se chama "literatura de diáspora" (para designar a escrita de uma comunidade emigrante suficientemente enraizada, com várias gerações, que já constitui uma extensão de uma outra comunidade base) levanta outros problemas em termos de critérios e classificações. Há, de facto, comunidades emigrantes que são pontes de passagem entre duas (ou mais) culturas. Como enquadrar a lite- 
ratura produzida nessa zona de contacto que é a comunidade a que se filiam por ascendência, e a qual se sobrepõe, em termos afetivos e identitários, àquela onde vivem e sobre a qual escrevem? Peter Nazareth, ele próprio nascido e criada no Uganda e, como diz na introdução, sem a menor noção do que seria literatura goesa até começar este projeto, parece acreditar que a comunidade de origem é critério suficiente. Penso que não é suficiente, e a questão é bem mais complexa, ${ }^{23}$ mas a verdade é que através desta antologia Peter Nazareth transmite-nos algo importante: sejam quais forem os critérios a definir e a metodologia a adotar, as ramificações africanas da literatura goesa são inegáveis. A título de exemplo sublinhe-se que Modern Goan Literature inclui excertos narrativos situados na Nigéria, Kenya, Zanzibar, Uganda, e até num barco ao largo de Aden, no Mar Arábico. A par destas obras, que representariam o que eu chamaria as ramificações africanas da expressão de uma diáspora goesa, Peter Nazareth inclui na sua antologia, além dos excertos de Orlando da Costa, um ensaio sobre Os Brâmanes, de Francisco Luís Gomes, bem como poemas de Manohar Rai Sardessai, Joseph Furtado e Eunice de Souza. Reúne assim escritores que escreveram em português, concani ou inglês, de épocas diferentes, e tanto aqueles que estavam baseados em Goa, como em diáspora. A literatura goesa é portanto multilingue/ plurilingue, e os seus contornos oscilam e perturbam classificações rígidas. Pode-se no entanto concluir que o aparecimento de uma rica e crescente literatura em língua inglesa produzida por autores goeses reflecte percursos migratórios e deve ser estudada como uma literatura de diáspora, isto é, em rede, desterritorializada em relação a um contexto geo-cultural específico que a defina ou circunscreva. É antes a comunidade goesa que como público e interlocutor se revê numa rede de contatos e rotas da diáspora que proporciona a esta literatura uma identidade própria, de conjunto, em toda a sua diversidade. Este facto implica, por parte dos críticos, a definição de padrões epistemológicos para se organizar a compreensão desta globalização de uma literatura que se quer manter afiliada a Goa, ao mesmo tempo local a transnacional. A escrita deste artigo é um contributo para a definição destes padrões, refletindo sobre o caso da literatura goesa em língua inglesa e sublinhando que a comunidade go-

2 As literaturas de diáspora têm um amplo debate em estudos literários de língua inglesa e facilmente se encontra bibliografia sobre o tema. Para uma introdução, veja Baubock e Faist (2010). 
esa já tem vindo a definir alguma espécie de cânone ao investir em traduções e antologias, pelo que a criação de vasos comunicantes entre as várias literaturas de Goa já existe e é de saudar.

\section{A diáspora em Goa}

Ao confirma-se a dimensão diaspórica/de emigração da vida cultural de Goa hoje em dia, faz falta olhar para a escrita de língua inglesa situada em Goa, e que dialoga com a sociedade goesa local, a qual também pode incluir narrativas de emigração a partir de um centro situado em Goa. É isso que faz Margaret Mascarenhas, num romance notável, Skin (2010), que, embora bem-sucedido a nível de vendas, não tem sido adequadamente estudado. Skin não é só uma história relativamente melodramática sobre várias gerações de uma família, como se poderia inferir de leituras superficiais, ou pouco informadas. É, pelo contrário, um romance que tem o mérito de inscrever a presença dos escravos africanos em Goa, e as suas relações, ora de extrema cumplicidade, ora como vítimas de abuso (incluindo tortura e assassínio) com a família goesa para quem trabalham, protótipo dos clãs aristocráticos indo-portugueses. No universo deste romance, no tempo presente, dito de "integração", "libertação" ou "pós-colonial", depois de se abolir a escravidão e o colonialismo, a sociedade goesa herdou da sua longa história relações de classe que também pressupõem a prestação de serviços. Entre a classe social mais privilegiada, racista e preconceituosa, a pele de cor clara é extremamente valorizada ("skin" quer dizer "pele" em inglês), facto que não é exclusivo a Goa. Em muitos dos romances de autoras indianas como Githa Hariharan, Arundhati Roy, Anita Desai, Nayantara Sahgal ou até mesmo na poesia de Eunice de Souza se encontram referências à importância da pele clara na procura de noivas, o que reflete valores transversais a vários contextos sociolinguísticos indianos. Possivelmente, esta valorização da pele clara tem a ver com o elevado estatuto social de algumas comunidades oriundas do Norte da Índia, que sempre olharam para o Sul com alguma sobranceria, e ter-se-á agudizado com a herança colonial, que era um regime político baseado em pressupostos racistas e eurocêntricos. $O$ tema do romance Skin questiona precisamente este ideal de pele clara associado a estatuto social e ao poder de oprimir outros, nomeadamente escravos e criados, ao longo de várias gerações de uma mesma 
família. A dimensão subversiva e liberadora do romance de Margaret Mascarenhas advém do facto de a matriarca, a branquíssima Dona Gabriela, ser a mais obscura das personagens pela sua crueldade e falta de carácter, estendendo-se a falta da qualidade humana a alguns outros membros das várias gerações de privilegiados. Como convém à vilã da narrativa, Dona Gabriela termina a sua vida rejeitada pela neta, a geração atual, que quebra com toda uma forma preconceituosa de pensar, escolhendo em termos de afetos e respeito a sua avó negra, afinal a verdadeira avó, pois Dona Gabriela havia roubado um dos bebés da família da sua criada para dar a um filho seu, casado, mas sem descendência. Note-se ironicamente, como em termos metafóricos, a falta de vigor dos privilegiados, as suas incapacidades, são afinal supridas pela apropriação do vigor de outros, que podem explorar. Skin é portanto um romance ousado, que tanto denuncia os horrores do racismo e da violência colonial, como cria cumplicidades inesperadas, para além de barreiras sociais. Se Dona Gabriela rouba uma criança à sua verdadeira mãe, como outros antes dela roubaram a vida, a força, os sonhos de gerações de escravos, também é uma mulher da sua família que galopa noite adentro para ir salvar os filhos gémeos da sua ama, roubados pelo marido desavindo. Não existem, na escrita de Mascarenhas, dicotomias sem ressalvas ou excepções, como convém a avisado retrato do mundo. Em segundo lugar, Skin é um romance que representa a vida dos goeses de hoje como uma vida em trânsito: a narrativa começa na América, passa por Angola, vem para Goa e termina com uma das personagens principais a viver parte do ano no Brasil. Um último detalhe revelador: Pagan ("pagã") é o nome da personagem principal. No seio de uma família católica, um nome como Pagan já sugere ao leitor a dimensão de ironia e de subversão que são fundamentais para se entender este texto em toda a sua riqueza. Margaret Mascarenhas parece querer confrontar formas de pensar estabelecidas. Confrontar o racismo é o mesmo gesto que escolher ser pagã em casa católica. Em ambos os casos, exemplarmente, a geração das personagens do presente escolhe estar perante o mundo de uma maneira crítica, o que se traduz no impacto do romance como literatura comprometida com a análise dos reflexos da história na sociedade atual. Da leitura de Skin pode-se concluir que a escrita literária contribui para a formação de uma consciência crítica em relação a processos históricos e sociais de abuso e exploração, que são assim denunciados. Fica também provado em termos de crítica literária como, de entre os temas que norteiam a literatura em língua inglesa de Goa, a questão 
da emigração, por escolha ou forçada (em virtude da escravatura e do colonialismo), é tema central neste cânone onde Margaret Mascarenhas tem um lugar conquistado.

Por fim, interpretar Skin impõe refletir-se sobre questões de narrativa familiar que se cruzam com a narrativa histórica oficial, visto que a história de gerações de uma mesma família é, afinal, o fio condutor do romance. Lívia, uma tia, decide começar a narrar a Pagan a história da sua família goesa:

Before the Portuguese came, we were Kamats - Saraswat Brahmins who had migrated from Northern India centuries earlier. One branch of the Kamat family converted to Catholicism in order to retatin their land and assets in the midsixteenth century. (MASCARENHAS, 2010, p. 28)

[Antes dos portugueses virem éramos Kamats - Saraswat Brahmins que tinham emigrado do norte da Índia séculos antes. Um ramo da família converteu-se ao catolicismo a fim de reter a sua terra e posses, em meados do século XVI.] (Minha tradução)

Embora seja um detalhe, sublinharia o humor de Mascarenhas que não deixa escapar a oportunidade para apontar motivações pragmáticas (e nada espirituais) para a conversão dos goeses. Mais importante é estabelecer a narrativa sanitizada, ordenadinha, e quase sem conflito nem indignidade que Lívia narra, transmitindo às gerações mais jovens a narrativa oficial. $O$ resto do romance revela a descoberta da outra versão da história, a verdadeira, que não é nem ordenada, nem recomendável, antes pautada por várias formas de violência e exploração. Apesar de tudo, a par de um certo humor, a narrativa propõe uma espécie de redenção na medida em que a verdade é reposta e Esperança se reúne com a sua neta Pagan, que é agora conhecedora do rapto de que foi vítima.

Se o redescobrir a verdade sobre si próprio implica rebuscar os esqueletos escondidos no arquivo oficial da história e da boa sociedade, então a deslocalização da literatura de Goa pela integração da experiência da emigração no seu sistema literário - sistema este simultaneamente enraizado nesse pequeno estado que é Goa e em sintonia com um universo mais abrangente, porventura global - traduz-se numa mais lúcida percepção da complexidade e simultaneidade das referências identitárias disponíveis e atuantes na afirmação de uma identidade colectiva goesa. Uma Goa ao mesmo tempo local e global, representada pela 
literatura da diáspora, permite ao leitor uma visão de Goa ao mesmo tempo "de fora" e "de dentro", ou seja, uma duplamente informada visão liminar, de fronteira (uso um conceito de Victor Turner ${ }^{3}$ ) que é a que expressa o estado intermédio de transformação, em que deixamos para trás o que já fomos (apenas uma literatura regional), e quando ainda não sabemos muito bem o que vamos ser num mundo em rede, que vive em ubiquidade, num eterno trânsito cibernético, mas sempre conectado a casa.

\section{A Índia em Goa e Goa na Índia}

Por fim, queria trazer a este debate a representação dos goeses na actual literatura indiana de língua inglesa. Procurei um exemplo de um autor muito reconhecido e lido, que abordasse estas temáticas, e a escolha recaiu, inevitavelmente, sobre um dos mais emblemáticos e premiados autores: Amitav Gosh, que escreveu uma trilogia sobre as chamadas "Guerras do ópio", na qual se confrontaram o regime colonial britânico e a China, pela primeira vez de 1839 a 1842, e uma segunda vez de 1856 a 1860 . Considerarei para este ensaio os primeiros dois livros da antologia, Sea of Poppies (2008) e River of Smoke (2011), dois romances sobre a produção e venda do ópio à China pelo império britânico. O circuito comercial começava no interior do território indiano, organizando-se depois o transporte do ópio para os portos indianos, e dai para o sudoeste da China. O contrabando do ópio para a China, a partir do delta do rio das Pérolas, causou uma crescente fricção entre ingleses e chineses, que desembocou nas ditas guerras. A questão central nestes romances é que os chineses têm o direito de se querer defender de uma droga com graves consequências sociais, enquanto que os ingleses, para além de não quererem abdicar deste lucrativo negócio, usam o contrabando do ópio como forma de ter acesso a outros produtos chineses, de alta qualidade, que eram então muito cobiçados, tais como tecidos e porcelanas.

Para além de descrever empreendimentos comerciais, rotas de navegação, soluções técnicas navais, a destruição do tecido agrícola indiano pela imposição de monocultura, a deslocação de populações para plantações, a exploração do

3 Cf. Turner (1969). 
trabalho indiano e a opressão das mulheres em ambas as sociedades (a indiana e a inglesa), Amitav Gosh ainda consegue ilustrar formas de espionagem científica (por parte dos agentes ingleses, em termos de sementes e plantas chinesas). Através desta série de subtemas específicos, estes romances focam ainda as relações coloniais entre ingleses, indianos e chineses, ilustrando rotas comerciais que implicam vários povos e agentes para além das mais óbvias dicotomias. Sublinhe-se que o rigor da investigação histórica que subjaz à ficção que Amitav Gosh escreve Ihe tem valido rasgados elogios por parte dos historiadores. O reconhecimento crítico a Gosh advém igualmente de um campo de estudos emergente, os Estudos do Oceano Índico, que procuram valorizar a produção de conhecimento sobre as trocas culturais, comerciais e demográficas entre vários países situados na zona do Índico, ao longo da história. Não será por acaso que Gosh foi o escritor convidado para redigir a apresentação do seminal livro de ensaios Eyes across the water (University of South Africa, 2010).

Para compreender a lógica dos romances de Amitav Gosh torna-se necessário invocar como campo teórico precisamente os Estudos do Oceano Índico, onde não tem interesse prioritário nem o porto de partida nem o porto de chegada onde aportavam gentes e bens. A novidade nesta procura de conhecimento é que se centra antes na viagem, no espaço líquido de intercâmbio, sem fronteiras nacionais, sem culturas dominantes de origem. Tudo é uma nova possibilidade. Entre estas novas possibilidades, o que interessa a Amitav Gosh é escrever a história do Índico, como esta se passou, isto é, relativizando a presença europeia, como mais um elemento apenas, entre os vários povos e etnias que se cruzaram nessas líquidas e instáveis geografias, sublinhando como o que se passava no mar tinha influência nas políticas que se definiam em terra, em territórios nacionais. Amitav Gosh escreve portanto uma história sobre o Oceano Índico, não só como ponto de passagem, mas como um espaço móvel com vida social própria, que tinha o poder de convocar novas comunidades improvisadas, ao reunir indivíduos das mais diversas origens no espaço limitado de um barco. A "trilogia do Íbis", como o autor lhe chama, sendo Íbis o nome de um barco, representa, em si, uma metáfora da atividade e energia que animou o Índico, palco de uma múltipla comunidade que vivia e prosperava há séculos, nos mares do Sudoeste da Ásia. O detalhe que me chamou a atenção nestes romances é que de entre as muitas comunidades indianas referidas, aparecem repetidamente os goeses, como um grupo com identidade própria, reconhecido por toda a gente. Passo a 
citar dois excertos que revelam esta inclusão dos goeses, como um grupo específico, entre os homens do mar por onde circulava o ópio:

(...) The only seamen who would venture on her decks (the Ibis') were lascars. This was Zachary's first experience of this species of sailor. He had thought that lascars were a tribe or a nation, like the Cherokee or Sioux: he discovered now that they came from places that were far apart, and had nothing in common, except the Indian Ocean; among them were Chinese and East Africans, Arabs and Malays, Bengalis and Goans, Tamils and Arawaknese. (GOSH, 2008, p. 14)

[(...) Os únicos marinheiros que se aventuravam no seu convés (só Ibis) eram os lascars. Esta era o primeiro contato de Zacarias com este tipo de marinheiros. Pensava que os lascars eram uma tribo ou nação, como os Cherokee ou Sioux: descobria agora que vinham de sítios muito variados e dispersos e não tinham nada em comum a não ser o oceano Índico; entre eles havia chineses, africanos da costa oriental, árabes, malaios, bengalis e goeses, tamils a caribenhos.] (Minha tradução)

ou:

Baburao's junk could be used to procure supplies from Macau, where masalas, daals, achars and other Achha comestibles were easy to find, because of the sizeable Goan population. (GOSH, 2011, p. 346)

[O junco (tipo de barco) de Baburao poderia ser usado para procurar provisões em Macau, onde Masalas, achars e outros produtos Acha eram fáceis de encontrar, por causa da significativa população goesa.] (Minha tradução)

O que eu vejo nestas duas citações é a reafirmação da importância da dimensão da emigração para se compreender o "ser goês" e a sua integração no Índico, independente da administração portuguesa, quando Goa ainda era uma colónia. Por outro lado, emerge como base identitária alternativa ao conceito de nação ou império o de "comunidade de origem", a par da "comunidade improvisada", móvel, sobre as águas (minhas designações). Dificilmente se poderia conceber melhor matriz identitária de fusão e partilha de um oceano, onde um autor indiano de referência não hesitou em representar os goeses, migrantes por excelência, com uma identidade colectiva própria, reconhecida como tal, apesar de 
em trânsito constante. Resta dizer, que na escrita, reconhecida e premiada de Amitav Gosh, a mistura de etnicidades, nações, comunidades, raças, religiões e géneros tem uma réplica surpreendente: as línguas francas utilizadas. Nestes dois romances em língua inglesa abundam palavras do bengali, francês, português e chinês, com tal mestria colocadas, que o leitor, qual Pirata do Índico, vai aprendendo as linguagens improvisadas que lê, para se entender nesse histórico e complexo universo oceânico, onde é convidado a entrar pela literatura, e onde Goa tem o seu lugar próprio.

\section{Referências}

AGWARVAL, Smita (ed.). Marginalized: indian poetry in English. Amsterdam: Rodopi, 2014. BAUBOCK, Rainer; FAIST, Thomas (eds.). Diaspora and transnationalism, concepts, theories and methods. Amsterdan: Amsterdam University Press: 2010.

GOSH, Amitav. Sea of poppies. London: John Murray, 2008.

GOSH, Amitav. River of smoke. New Delhi: Penguin Group, 2011.

GUPTA, Pamila; HOFMAEYR, Isabel Hofmeyr; PEARSON, Michael (eds.). Eyes across the water. Pretoria: Unisa Press/ Penguin India, 2010.

Indo-Portuguese Review. Calcutá: Indo-Portuguese Association, 1919-1933.

MACAULAY, Thomas. Minute on indian education. 1835. Disponível em:

$<$ https://www.google.pt/webhp?sourceid=chrome-instant\&ion=1\&espv=2\&ie=UTF-8\#q=

Thomas+Macaulay\%2C+Minute+on+Indian+Education>. Acesso em 26 jun. 2016.

MASCARENHAS, Margaret. Skin. Goa: 1556/ Broadway Publishing House, 2010.

MUHKERJEE, Meenakshi. Twice born fiction. New Delhi: Heinmann, 1971.

NAZARETH, Peter (ed.). Modern Goan Literature. Goa: 1556/ Broadway Book Centre, 2010.

PASSOS, Joana. Passos, Joana, Literatura poesa em português nos séculos XIX e XX: pers-

pectivas pós-coloniais e revisão crítica. Ribeirão: Editora Húmus, 2012.

PINTO, Rochelle. Between empires, print and politics in Goa. New Delhi: Oxford University Press, 2005.

TURNER, Victor. Liminality and communitas. In The ritual process: structure and antistrucuture. Chicago: Aldine Publishing, 1969. Disponível em: <http://www.sjsu.edu/ people/annapurna.pandey/courses/MSR122/s0/Victor-Turner-Liminality-and-Communitas.pdf $>$. Acesso em 26 jun. 2016.

VISHWANATHAN, Gauri. Masks of conquest. New York: Columbia University Press,1989.

Submetido em 27-06-16

Aprovado para publicação em 16-10-16 